\title{
AC 2008-1490: INSTRUMENTATION AND CONTROLS FOR AGRICULTURAL AND BIOLOGICAL ENGINEERING STUDENTS
}

\section{George Meyer, University of Nebraska-Lincoln}

GEORGE MEYER, Professor, has taught graduate and undergraduate classes that involve plant and animal growth and environmental factors, modeling, and instrumentation and controls for both agricultural and biological systems engineering students for 29 years. He has received national paper awards and recognition for his work in distance education and has received university teaching awards. His current research include measurement and modeling of crop water stress, fuzzy logic controls for turf irrigation management, and machine vision detection, enumeration, and plant species identification for spot spraying control and precision agriculture. 


\title{
Instrumentation and Controls for Agricultural and Biological Engineering Students
}

\begin{abstract}
Modern biological, biomedical, and agricultural systems use electronic sensors, instrumentation, and computers for acquisition of scientific data and for process control. Instrumentation is used for commercial product development, testing, and for basic research. An engineering course which addresses measurement principles, sensors, software, and characteristics of instrumentation and control systems with a variety of hands-on student activities will be discussed. This is a required course for two ABET accredited biological and agricultural engineering degree programs. Students of both programs participate and interact within this single course. The course assumes the student to be a junior, senior, or first year graduate student who has had an introductory electronics course and has completed a majority of the core and elective courses. The focus of student hands-on activities is through computer programming and hardware applications. Examples are presented in a draft book written by the instructor, who has taught this class for twenty years. Weekly laboratory activities include electrocardiogram, pulse oximetry, fuzzy logic temperature and humidity control, human exercise machines and energy exchange, insect detection and counting with optical sensors, $\mathrm{pH}$ controllers, and water flow measurements from small to large scale. Some activities are web-based bringing local research projects and instrumentation to the classroom. Student teams also develop semester projects starting at midterm. Those projects are presented as papers and posters during an annual department open house. A summary of selected student projects for the past four years and student assessments will be discussed.
\end{abstract}

Keywords: Courseware, biological systems, sensors, electronics, measurements, controls. 


\section{Course Concept}

Modern agricultural, biological, and biomedical instrumentation all use electronic sensors, analog and digital circuits, computers and microcontrollers for scientific measurements and process control. Instrumentation is used for commercial product development, testing, and basic research. The course described in this paper introduces basic measurement theory, applications of instrumentation and controls along with features of basic biological, environmental, and mechanical sensors. Sensors and transducers include contact, non-contact, mechanical, thermal, optical, ultrasonic, and other devices. A number of instrumentation books are currently available, either as monographs (Webster, 1999, Nachtigal, 1990, Mitchell, 1983, and others), textbooks (Daly, 1993, Carr, 1996, and others), or small, but significant paperbacks (Turner and Hill, 1999 and Ramsey 1996). Monographs are best used as library reserve resource materials. Some books feature a programming language for instrumentation and controls. Examples are Khalid (2000), Olansen and Rosow (2002), Travis and Kring (2006), and Khoo (1999). Many text books depend on the student's background to understand the material presented. A new text book being completed by the author also provides the student of this discipline an opportunity to understand and gain practical experience with modern measurement equipment, data acquisition, and digital control systems. The course assumes that the student is a junior, senior pre-engineer, or a first-year graduate student.

Thirteen topic areas of the course are presented in Table 1. The student begins with a study during week 1, the analysis of static and dynamic signals using an oscilloscope. Background is further enhanced by learning about features and capabilities of signal processing circuitry and digital acquisition. From that background, the student can select modern data logging equipment according to specifications which work best for obtaining measurement information for the problem at hand. Automation of measurements not only includes hardware but software. LabVIEW@ (www.ni.com or National Instruments, Austin, TX) programming is introduced using Bishop (2006). During the first five weeks, there is a concurrent and intensive introduction to LabVIEW and a review of fundamental instrumentation electronics. Instructional modules and examples are also available at various web-sites for demonstrating and simulating electronic circuits and responses. Many instrumentation textbooks cover analog and digital principles for instrumentation but in different orders and formats (e.g. Johnson, 2006, Northrop, 1997). Reinforcement of principles and introduction to practical instrumentation and control examples are offered through hands-on laboratory exercises, demonstrations, and preparation of a final team project. Laboratory exercises include experiments with temperature sensing, fluid flow, stress-strain, displacement, load-cell, ultra sound, and optical sensors. Computer interfacing with instrumentation is presented and includes the use of serial and parallel circuits, universal serial bus (USB), analog-to-digital, digital-to-analog, networking, and Bluetooth wireless applications. The team project begins at mid semester and is selected and approved from either a furnished list or according to student emphasis interests.

The new book in addition to measurement and sensor fundamentals emphasizes the use of an instrumentation programming language. Such a language should include both graphical or object oriented manufacturer interface support and script programming for specialized computations and control. LabVIEW as an example has a powerful parallel-like, data flow software system. The latest version can be facilitated by new multi core processors for better performance. LabVIEW 
also provides script programming which has distinctive customizing advantages. Mathscript ${ }^{\circledR}$ as a subset of MATLAB ${ }^{\circledR}$ script (The Mathworks, Natick, MA) is primarily a top-down computational language, with a number of special functions for processing large data sets and arrays. (Our students learn MATLAB as freshman.) Mathscript is especially useful for adaptive modeling, where real time data drives a model. Examples include plant water use measurements using a first law energy balance or preprocessing data and inputs to a proportional-integral -differential or a fuzzy logic controller. Psychrometric calculations for a sensible, latent heat, and radiation analyses of heat exchange from a moist surface is best handled by Mathscript.

Table 1. Instrumentation and Controls - Schedule of Topics.

\begin{tabular}{|l|l|}
\hline \multicolumn{2}{|l|}{ Tentative Weekly Schedule of Topics - Fall $\mathbf{2 0 0 7}$} \\
\hline Week 1 & $\begin{array}{l}\text { Measurements for Physical and Biological Systems - } \\
\text { Oscilloscope. }\end{array}$ \\
\hline Week 2 & Analog signal conditioning. \\
\hline Week 3 & LabVIEW Exercises (Bishop). \\
\hline Week 4 & Digital signal processing (NI, MCC, and LabJACK). \\
\hline Week 5 & LabVIEW Exercises (Bishop). \\
\hline Week 6 & Sound and Ultrasound measurements. \\
\hline Week 7 & Thermal Sensors and Temperature Transducers. \\
\hline Week 8 & Force and Strain Sensors. \\
\hline Week 9 & Velocity and Flow Sensors. \\
\hline Week 10 & Optical Sensors and Machine Vision (NI IMAQ®). \\
\hline Week 11 & Introduction to Fuzzy Controls (NI Controls Add-on). \\
\hline Week 12 & Introduction to Classical Controls. \\
\hline Week 13 & $\begin{array}{l}\text { Final Controls: Stepper motors, modutrols, and actuators } \\
\text { (time permitting). }\end{array}$ \\
\hline
\end{tabular}

Over the years, it had become apparent that many instrumentation textbooks have been written for special audiences in various fields of engineering. There has also been a recent proliferation of instrumentation monographs, many of which are included in the reference list. Monographs and refereed instrumentation papers are certainly of interest to senior agricultural and biological engineers, but may not provide the practice exercises needed. If one searches the internet, they will find numerous commercial sensors and instrumentation sites, and possibly be overwhelmed by the plethora of technical information. Sufficient background and experience to evaluate and select such systems is what is really needed.

The course provides the student the opportunity to operate modern electronic measurement equipment, including an oscilloscope, data acquisition, microcontrollers, and digital control systems. The course assumes the student has had a basic physics course and has taken most of the core agricultural and biological systems engineering courses. This course addresses practical instrumentation and control systems through hands-on laboratory exercises, in-class 
demonstrations, and a semester student team project. Student teams present their projects as posters during the annual Department Open House in December.

\section{Course Objectives}

The objectives and expected outcomes of this course are to ${ }^{1}$ :

1. learn the technical language, terms, and definitions for electronic sensors and instrumentation. Acquire technical skills for selecting and using electronic sensors and modern data-logging equipment. (knowledge),

2. develop an understanding of the physical mechanisms of basic sensors and how they interact with the measurand in biological, biomedical, and agricultural applications. (comprehension),

3. enhance the ability to select components, design, assemble, and operate measurement systems for specific applications (application),

4. learn basic analytical and research skills to aid in selecting and applying instrumentation for specific applications, first by understanding the process, and then applying the measurement system (Analysis),

5. provide the student the opportunity to design, develop and present a specific measurement system relative to his /her area of technical interest and choice (synthesis),

6. provide the opportunity to use and improve oral and written communication skills to describe the development, evaluation, and performance of an electronic instrumentation system. Provide the basis for understanding the need for life-long learning of new measurement systems (evaluation).

\section{Laboratory Exercises}

The first nine weeks of the semester are devoted to formal laboratory exercises and preparation of good lab reports. Laboratory reports are often limited to a two-page narrative, typical of the size expected by industry. The dynamics and characteristics of electronic sensors are very important in measurements. During the first lab, students learn how to operate a modern digital Tektronix 1002b oscilloscope (www.tek.com). Students analyze unknown signals provided by a signal generator, which include sinusoidal, square, and impulse signals. This includes a fast Fourier transform to analyze signal and noise frequencies. The second lab is devoted to wiring and soldering skills (a lost art) in the construction of a microphone circuit. The response time of sensors and the aperture time of sample frequency of analog-digital conversion are important in matching instrumentation to desired measurement objectives. The students study the response time of various temperature sensors which include thermocouple, thermistors, integrated temperature sensors, and infrared sensors. The student design and build a Lab VIEW virtual instrument (VI) logger using a LabJack (www.labjack.com) or other USB type multifunction device (Figure 1), commercially available. From there, the student proceeds to temperature measurements, force measurements (using an arm strength torque device with strain gages (Figure 2) and an instrumented exercise bike with flexiforce thin-film sensors on the pedals (Figure 3). A fuzzy logic temperature control exercise is also implemented using the LabVIEW Controls

\footnotetext{
${ }^{1}$ Corresponding to Bloom's Taxonomy (Bloom, 1956).
} 
Add-on as shown in Table 2 (Ross, 2004, Mamdani, 1974, and Zadeh, 1965) ${ }^{2}$.

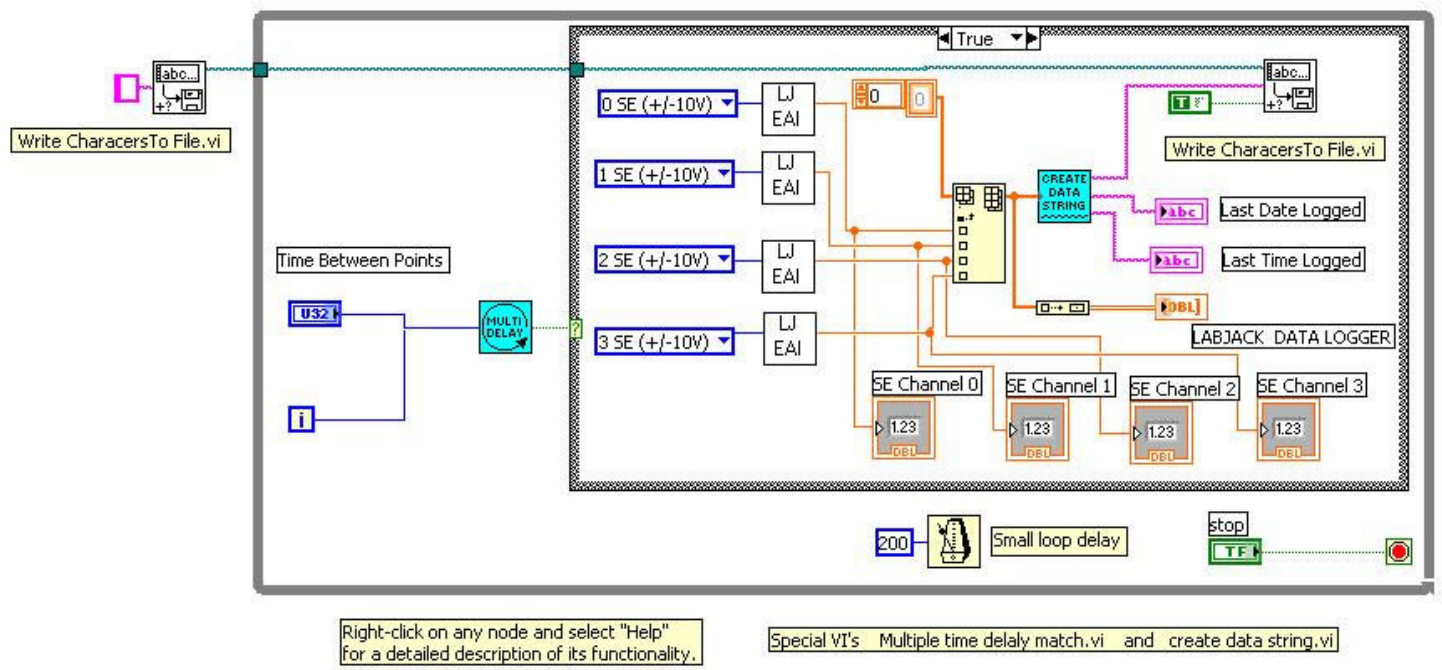

Figure 1. Block diagram for the LabJack data logger virtual instrument (VI).
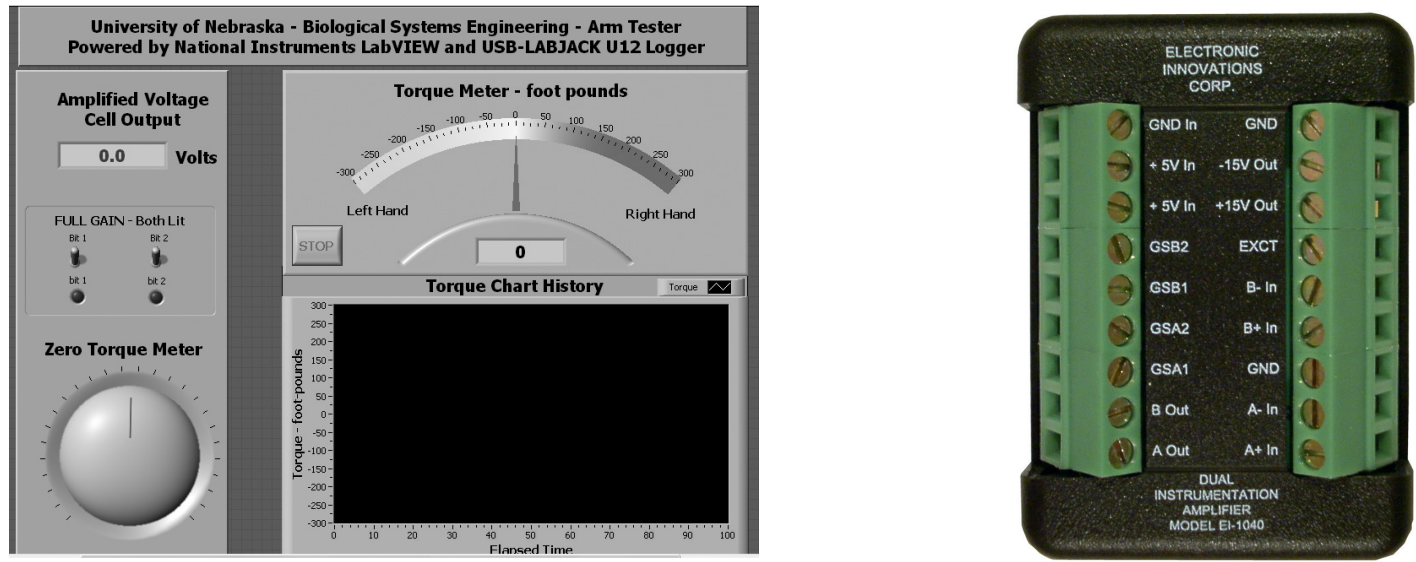

Figure 2a. Front Panel for the Arm Wrestler virtual instrument (VI).

Figure 2b. Instrumentation Amplifier (courtesy: www.labjack.com).

Table 1. Linguistic Antecedents and Consequences for a Temperature Fuzzy Controller.

\begin{tabular}{|c|c|c|c|c|c|}
\hline \multirow{2}{*}{$\begin{array}{l}\text { Temperature } \\
\text { Change }\end{array}$} & \multicolumn{5}{|c|}{ Current Temperature is: ${ }^{0} \mathrm{C}^{1}$} \\
\hline & Far Below & Near Below & Set Point & Near Above & Far Above \\
\hline $\begin{array}{l}\text { Fast decrease } \\
\text { (F-D) }\end{array}$ & $\begin{array}{l}\text { I-100 or } \\
\text { High heat, Fan } \\
\text { Off }\end{array}$ & $\begin{array}{l}\text { I-100 or } \\
\text { Medium Heat } \\
\text { Fan Off }\end{array}$ & $\begin{array}{l}\text { I-50 or } \\
\text { Medium Heat } \\
\text { Fan Off }\end{array}$ & $\begin{array}{l}\text { I-50 or } \\
\text { Low Heat } \\
\text { Fan On }\end{array}$ & $\begin{array}{l}\text { N_C or } \\
\text { Heat Off } \\
\text { Fan On }\end{array}$ \\
\hline $\begin{array}{l}\text { Slow Decrease } \\
\text { (S-D) }\end{array}$ & $\begin{array}{l}\mathbf{I - 1 0 0} \text { or } \\
\text { High Heat } \\
\text { Fan Off }\end{array}$ & $\begin{array}{l}\text { I-50 or } \\
\text { Low Heat } \\
\text { Fan Off }\end{array}$ & $\begin{array}{l}\text { I-50 or } \\
\text { Low Heat } \\
\text { Fan On }\end{array}$ & $\begin{array}{l}\mathbf{N \_ C ~ o r ~} \\
\text { Low Heat } \\
\text { Fan Off }\end{array}$ & $\begin{array}{l}\mathbf{R - 5 0} \text { or } \\
\text { Heat Off } \\
\text { Fan On }\end{array}$ \\
\hline No Change (NC) & $\begin{array}{l}\text { I-50 or } \\
\text { Medium Heat } \\
\text { Fan Off }\end{array}$ & $\begin{array}{l}\text { I-50 or } \\
\text { Low Heat } \\
\text { Fan On }\end{array}$ & $\begin{array}{l}\text { N_C or } \\
\text { Heat Off } \\
\text { Fan Off }\end{array}$ & $\begin{array}{l}\text { R-50 or } \\
\text { Heat Off } \\
\text { Fan On }\end{array}$ & $\begin{array}{l}\text { R-50 or } \\
\text { Heat Off } \\
\text { Fan On }\end{array}$ \\
\hline $\begin{array}{l}\text { Slow Increase } \\
\text { (S-I) }\end{array}$ & $\begin{array}{l}\text { R-50 or } \\
\text { Medium Heat }\end{array}$ & $\begin{array}{l}\text { N_C or } \\
\text { Low Heat }\end{array}$ & $\begin{array}{l}\mathbf{R - 5 0} \text { or } \\
\text { Heat Off }\end{array}$ & $\begin{array}{l}\mathbf{R - 5 0} \text { or } \\
\text { Heat Off }\end{array}$ & $\begin{array}{l}\text { R-100 or } \\
\text { Heat Off }\end{array}$ \\
\hline
\end{tabular}

${ }^{2}$ Mention of commercial products or trade names are for reference only and not to the exclusion of others that might be suitable. 


\begin{tabular}{|l|l|l|l|l|l|}
\hline & Fan Off & Fan Off & Fan On & Fan On & Fan On \\
\hline Fast Increase (F-I) & N_C or & R-50 or & R-50 or & R-100 or & R-100 or \\
& Low Heat & Low Heat & Heat Off & Heat Off & Heat Off \\
& Fan Off & Fan On & Fan On & Fan On & Fan On \\
\hline
\end{tabular}

Relative to the set-point.

${ }^{2}$ Equipment used.

1. LabJack U12 Logger (www.labjack.com).

2. Type $\mathbf{J}$ thermocouple with monolithic thermocouple amplifier and cold junction.

3. Infrared temperature Sensor

4. A handheld independent digital voltage meter.

5. Thermos filled with ice and hot water and a precision alcohol thermometer to measure and check thermocouple readings.

6. An infrared black-body plate to check infrared sensor readings.

7. Digital-to-Analog (DAC) Control Unit for 110-volt, lamp heater.

8. On-Off Control Unit for the Fan.

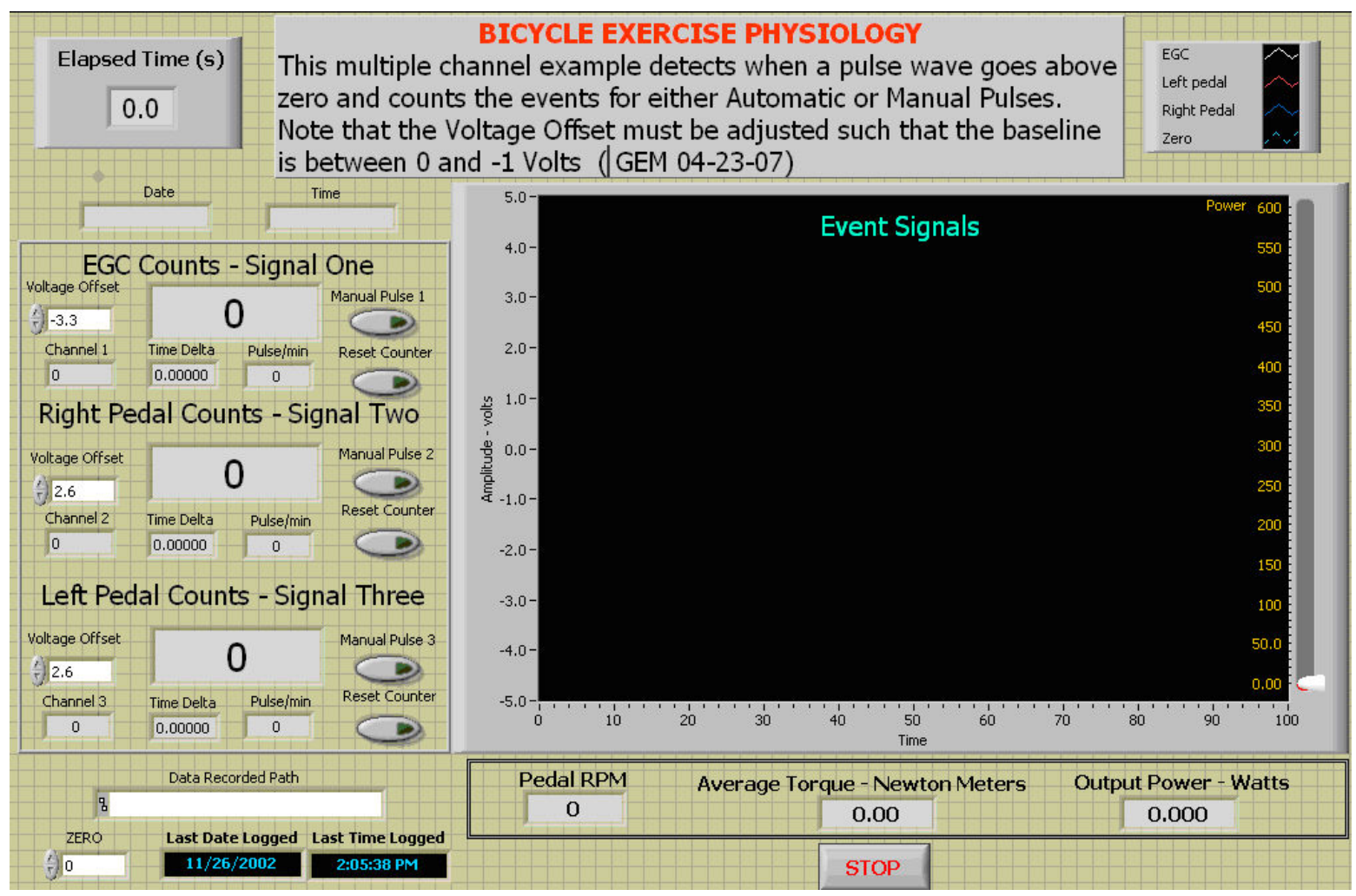

Figure 3. Front Panel of a LabVIEW exercise bike virtual instrument (VI).

\section{Student Team Projects}

The final six weeks of the class are devoted to student team projects. Team student instrumentation and controls projects are selected from a prescribed list provided by the instructor. The students developed the projects as a group and presented them as posters at an annual Department open house. The open house includes invited other students, alumni, faculty, administrators and potential employers. Team sizes are either two or three members. The principles of Michaelsen, et al. (2004 and 2007) are considered in team group planning and facilitation. The final written term paper was graded according to the instrument shown in 
Appendix B. A brief summary description of selected projects for the years 2004-2007 are given below. The major pieces of electronic equipment are also given.

\section{Ultrasonic Measurement of Water Levels with an Embedded System (2007).}

The area of ground water and surface water interactions is an important political issue in Nebraska. The most well known example is that of the Republican River basin in Southwest Nebraska where irrigators have been asked to shut down wells due to a perceived impact on ground water base flow and hence surface water flows in the River as it flows into Kansas. It is very likely that there are periods during an irrigation season where ground water levels are adequate to provide base flow to rivers and streams. Basic equations are described in hydrogeologic literature that can be used to estimate ground water discharge into a river or stream. In general, these equations consider factors such as aquifer hydraulic conductivity, stream bed conductance, and the relative water levels between the river and the adjacent ground water. By applying real time monitoring of the relative water levels between a river or stream and it's adjacent ground water, it would be possible to immediately assess if a ground water to surface water discharging or recharging condition was occurring.

Equipment: Basic Stamp 2® with $32 \mathrm{MHz}$ processor (www.parallax.com), ultrasound range finder transducer, serial Bluetooth to a laptop computer, LabVIEW 8.2.1 (VISA).

\section{Development of an acoustics based instrumentation system for eggshell quality} monitoring (2007).

Eggshell quality is an important factor in egg production. Shells with varying strengths are preferred for different applications. For example, table eggs require strong shell to prevent handling damages; where as hatching eggs require thin shell to facilitate gas exchange and the chick to crack the shell during the hatching process. Another problem with automated egg production line is detecting eggs with defects such as cracks, blood spots and meat spots. Cracked eggs are more vulnerable to bacterial infections; where as eggs with blood spot or meat would potentially degrade their value. The procedure used for eggshell quality assessment, candling, is a subjective, tedious, time consuming process and it requires skilled personnel. At times, it is very hard or even impossible to perceive tiny cracks on the shell by human inspectors. Hence, it is important to detect eggs with unfit shells and remove them from further incubation, and processing. The objective of this project was to develop an acoustics based (either impulse response or ultra sound) instrumentation setup for investigating eggshell strength and detecting eggshell defects.

\section{The Energy Balance of Turf Grass System in an Environmental Chamber (2007)}

This team project was an investigation and measurement of the energy components for latent and sensible heat and the radiation balance for flats of irrigated and non-irrigated blue grass turf. Continuous measurements of temperature, humidity, canopy temperature, and short and long wave radiation were taken in Chase Hall environmental chamber simulating an early Spring day. The energy balance was based on the first law of Thermodynamics, but included estimates of stomata and aerodynamic resistances. A web-based instrumentation demonstration and a webcam were presented at the open house using a laptop with wireless internet connection. 
Equipment: Measurement Computing® USB-5203 (Norton, MA), LabJack U12, temperature and relative humidity probe, infrared temperature sensors, thermocouples, pyranometers, wet-bulb psychrometers, thin film load cell lysimeters for flats, web cam, and LabVIEW 8.2.1 and IMAQ®.

\section{An Automatic Water Turbidity Sensor (2006).}

Water quality measurements using optical sensors for waster water treatment discharged water. Using the broken pipe VI exercise, the team actuated a check valve to take a sample from a water line and deposit it into a holding container. Using an optical sensor a reading was taken on total suspended solids in the sample based upon light scattered transmitted or reflected. The project required analysis of wavelengths, calibration of sensors and error analysis.

Equipment: LabJACK U12, commercial turbidity kit, photo diodes, solid state relay, water tank, and LabVIEW 8.

\section{Control of an Ethanol Fermentation Process (2006).}

A fermentation process in continuous production of ethanol requires monitoring and maintaining parameters such as temperature, $\mathrm{pH}$, and flow rate. Fermentation by yeast requires optimum temperature in the range of $37^{\circ} \mathrm{C}$, and $\mathrm{pH}$ of 5 . The temperature can be controlled by switching on or off a heater system. The $\mathrm{pH}$ can be controlled by adding acid or $\mathrm{NaOH}$. These adjustments have to be done rapidly to improve the efficiency of the fermentation process. Both proportional-integral-derivative (PID) controller and fuzzy logic controller were compared for controlling the process variables. Control accuracies and response timings of both controllers were reported. LabVIEW and the Controls add-on were used for building the controls to monitor the process.

Equipment: LabJACK U12, two solid-state relays (SSR), thermocouple cold bridge modules, flow meter, and LabVIEW 8.

\section{Design and Implementation of LabVIEW Software in a Functional Home Security System (2006).}

As part of the semester project, the group decided to design a functional home security system using LabVIEW software. The difference between the proposed security system and the ones commercially available is that the proposed system can be operated using a home PC and adapted to any complex infrastructure of a modern home. In addition to ease of adaptation, customization of the signals will be possible through voice instruction and warnings; the voice could be from the users instead of a preset audio file playback. Status of the system could be monitored from an intranet or internet connection. The scope of this project is limited to a two room house with one window in each room.

Equipment: LabJACK U12, microphone, motion sensor, 2-solid state relays (SSR), notebook computer, and LabVIEW 8. 


\section{Optical insect/beetle detection trap (2006)}

This team designed and tested a three-sensor optical insect/beetle detection and enumeration system. An express virtual instrument counter was programmed with an analog voltage logger and was used to threshold pulse counts using cockroaches passing through the device.

Equipment: LabJACK U12, photo diodes, resistors, 1.5-inch diameter PVC tube, and LabVIEW 8.

\section{An Analysis of the Quarter Scale tractor for Strength under Dynamic Loading (2005)}

An important aspect of the national quarter-scale tractor design competition was correct sizing of structural components to meet strength requirements while minimizing material, cost, and weight. The 2005 quarter scale tractor was designed using the Solid Works® (Concord, MA) design program, so a theoretical analysis of frame stresses was also accomplished, but needed experimental verification. Using a, the team strategically placed strain gauges on different parts of the tractor frame to determine actual stress and strains, during a dynamic loading test. With this data, more accurate predictions of the strength and integrity of this year's tractor design were achieved.

Equipment: Campbell Scientific CR5000 (Logan, UT), strain gage amplifier, and strain gages.

\section{Ergonomic Improvements to an On-the-go Weed Scouting System (2005)}

A certified commercial crop consultant is currently scouting and mapping weeds and providing herbicide recommendations to growers. His system uses an all-terrain-vehicle (ATV) and a hand-held portable-data-acquisition device (PDA) along with a global positioning system (GPS) to record visually sighted weeds and estimated populations. This team project developed a simple hand control, switches, and LED species indicators for data entry to improve the efficiency and accuracy of the weed mapping process. The method for traversing tram lines for visual assessment of weeds continues to be a successful enterprise by the crop consultant and is featured at: (http://www.deere.com/en_US/ag/pdf/furrow/2007/summer_07_F0702816.pdf).

Equipment: Motorola 6811 embedded controller with switch and LED interface.

\section{Analyzing Heat Loss during Water Induced Hypothermia (2005)}

Hypothermia is a drop in the human core temperature associated with heat loss from the body. Hypothermia is experienced widely during outdoor activities every year. In this project, infrared measurements of skin and ambient temperatures were taken of a subject under two conditions, with and without a wet suit in a cold swimming pool. Comparing these two temperature sets, heat loss rates was computed. This analysis helped to demonstrate the effectiveness of a wet suit and their benefit to swimmers in cold water. The equations of DuBois and DuBois (1961) were used for body surface area.

Equipment: Hand-held infrared thermometer, air temperature and humidity meter. 
11. Determination of Pear Quality Using Machine Vision and an Electronic Nose (2004).

Marketable fruit quality is a subjective set of measurable quality factors, and represents a major problem for human graders, in determining how these factors should be combined for grading decisions. This project used an electronic nose and machine vision as a fusion method for determining fruit ripeness and/or quality. To do the classification, fuzzy inference systems were trained using the nose to recognize different aromas, based on ripeness and/or quality. Machine vision was used to analyze color and shape and develop criteria for fruit quality and/or ripeness. The end goal was to use multi-sensor data acquisition to determine fruit quality/ripeness using the various input parameters.

Equipment: Cyrano electronic nose (Cyrano Sciences, inc., Pasadena, CA), color digital camera, MATLAB with Fuzzy Logic, and Image Processing Toolboxes.

\section{Mice Detection Using Sounds (2004).}

The purpose of this project idea was to detect rodents or rodent activity using sound in food storage areas. The project will use the sound card of a personal computer as a sensor. Computer programs were written to first record and then analyze laboratory mice noises and vocalizations. The animal sounds were analyzed as a particular range of frequencies that are distinguishable when graphically analyzed. The main difficulty of the project was to determine this range of frequencies. A final goal of this project was to develop a method to detect not only the presence, but possibly the exact location of rodents.

Equipment: Camcorder to record mice sounds and computer with an audio card and software.

\section{Student Acceptance}

Class size has ranged from 20 to 33 students. Student reaction to this class has been very good. The overall class score was $(3.01 \pm 0.15 / 4.0)$. The overall instructor score was $(3.46 \pm 0.48 / 4.0)$. Students were quite complimentary about the course and that the instructor did a good job. The material was considered very relevant. Examinations were fair, but long. Improvements could be made in the new textbook. Posters at the open house were well-done. Project reports were well-written.

\section{Bibliography}

1. Bishop, R.H., 2006. LabVIEW 8 Student Edition. Prentice Hall, Upper Saddle River, NJ.

2. Bloom, B. S., 1956. Taxonomy of Educational Objectives: The Classification of Educational Goals. Susan Fauer Company, Inc., pp.201-207.

3. Carr, J.J., 1996. Elements of Electronic Instrumentation and Measurement, Prentice Hall, Englewood Cliffs, NJ.

4. Dally, J.W., W.F. Riley, and K.G. McConnell, 1993. Instrumentation for Engineering Measurements, Second Edition. John Wiley and sons, inc., New York.

5. DuBois, D. and E.F. DuBois, 1961. A formula to estimate the approximate surface area if weight and height are known. Archives of Internal Medicine, 17:863-871.

6. Johnson, C.D., 2006. Process Control Instrumentation Technology $\left(8^{\text {th }}\right.$ Edition). Pearson, Prentice Hall. Columbus, $\mathrm{OH}$. 
7. Khalid, S.F., 2000. LabWindows/CVI Programming for Beginners. Prentice Hall, Upper Saddle River, NJ.

8. Khoo, M.C.K., 1999. Physiological Control Systems. IEEE Press, NY.

9. Mamdani, E., 1974. Application of fuzzy algorithms for control of a simple dynamic plant Proc. IEEE, 1585-1588.

10. Michaelsen, L.K., D.X. Parmelee, K.K. McMahon, and R.E. Levine. 2007. Team-Based Learning for Health Professions Education: A Guide to Using Small Groups for Improving Learning, Stylus Publishing, Sterling VA.

11. Michaelsen, L.K., A.B. Knight, and L.D. Fink. 2004. Team-Based Learning: A Transformative Use of Small Groups in College Teaching, edited by Stylus Publishing, Sterling VA.

12. Mitchell, B.W., 1983. Instrumentation and Measurement for Environmental Sciences. American Society of Agricultural Engineers, St. Joseph, MI.

13. Nachtigal, C.W., 1990. Instrumentation and Controls, Fundamentals and Applications. John Wiley and sons, NY.

14. National Instruments: LabVIEW Fuzzy Logic for G Toolkit Reference Manual. 1997.

15. Northrop, R.B., 1997. Introduction to Instrumentation and Measurements. CRC Press, NY.

16. Olansen, J.B. and E. Rosow, 2002. Virtual Bio-Instrumentation. Biomedical, Clinical, and Healthcare Applications in LabVIEW. Prentice Hall, NY.

17. Ramsay, D.C., 1996. Principles of Engineering Instrumentation, John Wiley and sons, NY.

18. Ross, T.J., 2004. FUZZY LOGIC with Engineering Applications. John Wiley \& Sons, NY.

19. Travis, J. and J. Kring, 2006. LabVIEW for Everyone. Prentice Hall, NY.

20. Turner, J. and M. Hill, 1999. Instrumentation for Engineers and Scientists. Oxford Science Press, NY.

21. Webster, J.G., 1999. The Measurement, Instrumentation, and Sensors Handbook. CRC and IEEE Press., Baca Raton, FL.

22. Zadeh, L., 1965. Fuzzy Sets, Inf. Control 8:338-353.

\section{Appendix A}

Catalog Description:

Text Books:
Instrumentation and Controls ( 3 cr) Lec 2. Lab 2. Prereq: Analysis and design of instrumentation and controls for agricultural and biological production, management, and processing. Theory of sensors and transducers, analog and digital electrical control circuits, and the interfacing of computers with instruments and controls. Emphasis on signal analysis and interpretation for improving system performance.

LABVIEW 8 Student Edition (includes Version 8.2 SW) National Instruments, Inc. by Robert Bishop, The University of Texas at Austin. ISBN: 0-13-199918-4, Publisher: Prentice Hall, Copyright: 2007.

Instrumentation and Controls For Agricultural and Biological Engineering Applications using LabVIEW@ as a Software Support System (Draft) by G.E. Meyer.

Format: $\quad$ This course is 3 credits ( 2 weekly lectures and a two-hour laboratory). 
Appendix B. FINAL REPORT - SCORE SHEET - 125 Points

\begin{tabular}{|c|c|c|c|}
\hline CATEGORIES & $\begin{array}{l}\text { POSSIBLE } \\
\text { POINTS }\end{array}$ & $\begin{array}{l}\text { POINTS } \\
\text { GIVEN }\end{array}$ & COMMENTS \\
\hline SIGNED LETTER OF TRANSMITTAL & \multicolumn{3}{|c|}{$\begin{array}{l}\text { Report must be signed by all team members, } \\
\text { signifying all have contributed! }\end{array}$} \\
\hline \multicolumn{4}{|l|}{ REPORT CONTENT AND FORMAT } \\
\hline Summary - Single descriptive paragraph or abstract. & 5 & & \\
\hline $\begin{array}{l}\text { Background and Literature Review - Cites useful } \\
\text { literature, previous instrumentation approaches, and } \\
\text { describes purpose and impact of the project. }\end{array}$ & 15 & & \\
\hline Objectives - Overall objective and 1-2 sub objectives. & 5 & & \\
\hline $\begin{array}{l}\text { Procedure/ Methods - Sensors used. Data acquisition } \\
\text { method. Appropriate equations, units, numbered, and } \\
\text { cited. Refers to sample calculations or results in } \\
\text { appendix. Support with pictures, figures and/or tables, as } \\
\text { appropriate. }\end{array}$ & 20 & & \\
\hline $\begin{array}{l}\text { Results and Discussion - Reports details and results of } \\
\text { development efforts, methods, testing, with table and } \\
\text { figure support. }\end{array}$ & 20 & & \\
\hline $\begin{array}{l}\text { Conclusions - Appropriate conclusions that match } \\
\text { objectives. Suggestions for future work. }\end{array}$ & 10 & & \\
\hline References (Complete citations - ASAE method). & 5 & & \\
\hline $\begin{array}{l}\text { Figures and Tables - Appropriate amount of significant } \\
\text { digits, information displayed, correctly justified, labeled, } \\
\text { footnotes, and captions in the correct position. } \\
\text { Landscapes attached correctly to the report. Stands by } \\
\text { themselves. }\end{array}$ & 10 & & \\
\hline $\begin{array}{l}\text { Appendices - Appropriate supporting material. Examples: } \\
\text { computer code used, manufacturer's specific sheets, } \\
\text { sample calculations, samples of raw data, and cost data } \\
\text { (not required, unless requested). }\end{array}$ & 10 & & \\
\hline OVERALL REPORT APPEARANCE & $\mathbf{0}$ & & \\
\hline $\begin{array}{l}\text { Neatness and Writing Quality - Proper spacing, } \\
\text { justification, proper grammar, correct spelling, and page } \\
\text { numbers. Drawings and sketches are neat and properly } \\
\text { labeled. }\end{array}$ & 15 & & \\
\hline $\begin{array}{l}\text { Overall Creativity - Shows interest and enthusiasm in } \\
\text { project. }\end{array}$ & 10 & & \\
\hline FINAL TOTAL SCORE & 125 & & \\
\hline
\end{tabular}

